\title{
Trajetórias Histórico-políticas da Formação Inicial de Professores da Educação Básica no Brasil
}

\author{
DEROSSI, Caio Corrêa ${ }^{1}$ \\ CARVALHO, Thaís Carneiro ${ }^{2}$
}

\section{RESUMO}

No presente artigo de abordagem qualitativa e de naturezas bibliográfica e documental, far-se-á um debate sobre os aspectos histórico-políticos da formação inicial de professores que atuarão na educação básica. Para tanto, por meio da literatura especializada e de documentos legais e curriculares que versam sobre a formação inicial e o trabalho dos profissionais da educação, o texto percorrerá um recorte de longa duração, com a finalidade de propor por meio de uma visada histórica e panorâmica, os percursos acerca da formação. Como considerações finais, pode-se entender que o processo formativo de professores foi alvo de disputas e correspondia em sua maioria aos interesses políticos. Ainda nesse sentido, em relação aos arranjos legais, identificou-se que as propostas e efetivações curriculares eram dissonantes em relação a defesa realizada por fóruns e associações profissionais, que concebiam a docência como núcleo central para a formação docente na educação básica brasileira.

Percursos histórico-políticos. Formação inicial de professores. Docência para a educação básica.

\section{Historical-political trajectories of initial training for basic education teachers in Brazil}

\begin{abstract}
In this article with a qualitative approach and bibliographic and documentary in nature, a debate will take place on the historical-political aspects of the initial training of teachers who will work in basic education. For this, through the specialized literature and legal and curricular documents that deal with the initial training and the work of education professionals, the text will cover a long duration, with the purpose of proposing through a historical and panoramic view, the paths about training. As final considerations, it can be understood that the teachers' training process was the subject of disputes and corresponded mostly

\footnotetext{
${ }^{1}$ Mestrando pelo Programa de Pós-Graduação em Educação da Universidade Federal de Viçosa (UFV). E-mail: derossi.caio@gmail.com. Lattes:

http://lattes.cnpq.br/2861629420221016. Orcid: http://orcid.org/0000-0001-9762-7392.

${ }^{2}$ Mestranda pelo Programa de Pós-Graduação em Educação na Universidade Federal de Viçosa. E-mail: thaiscarvalho471@gmail.com. Lattes: http://lattes.cnpq.br/4748641135055179. Orcid: http://orcid.org/0000-0002-6556-2122.
}

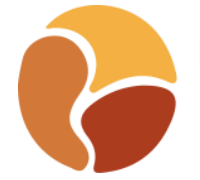


to political interests. Still in this sense, in relation to the legal arrangements, it was identified that the curricular proposals and implementations were dissonant in relation to the defense carried out by forums and professional associations, which conceived teaching as the central nucleus for teacher education in brazilian basic education.

Historical-political paths. Initial teacher training. Teaching for basic education.

\section{Trayectorias histórico-políticas de la formación inicial de profesores de educación básica en Brasil}

\section{RESUMEN}

En este artículo de enfoque cualitativo y de carácter bibliográfico y documental, se debatirá sobre los aspectos histórico-políticos de la formación inicial de los docentes que trabajarán en la educación básica. A través de la literatura especializada y los documentos legales y curriculares que abordan la formación inicial y el trabajo de los profesionales de la educación, el texto abarcará un espacio de larga duración, con la finalidad de proponer a través de una mirada histórica y panorámica, los caminos de la formación. Como consideraciones finales, se puede entender que el proceso formativo del profesorado fue objeto de disputas y correspondió mayoritariamente a intereses políticos. Aún en este sentido, en relación a los ordenamientos jurídicos, se identificó que las propuestas e implementaciones curriculares fueron disonantes en relación a la defensa realizada por foros y asociaciones profesionales, que concebían la docencia como el núcleo central de la formación docente en la educación básica brasileña.

Caminos histórico-políticos. Formación inicial del profesorado. Docencia para la educación básica.

\section{Traiettorie storico-politiche della formazione iniziale degli insegnanti di istruzione di base in Brasile}

\section{SOMMARIO}

In questo articolo con un approccio qualitativo e di natura bibliografica e documentaria, verranno discussi gli aspetti storico-politici della formazione iniziale degli insegnanti che opereranno nell'istruzione di base. Attraverso letteratura specializzata e documenti giuridici e curriculari che affrontano la formazione iniziale e il lavoro dei professionisti dell'educazione, il testo coprirà uno spazio a lungo termine, al fine di proporre attraverso una visione storica e panoramica, i cammini di formazione. Come considerazioni finali, si può comprendere che il processo di formazione degli insegnanti è stato oggetto di controversia e corrispondeva principalmente a interessi politici. Anche in questo senso, in relazione agli ordinamenti giuridici, si è individuato che le proposte e le implementazioni curriculari risultano dissonanti rispetto alla difesa svolta da 
forum e associazioni professionali, che hanno concepito la didattica come nucleo centrale della formazione dei docenti nell'istruzione di base Brasiliano.

Percorsi storico-politici. Formazione iniziale degli insegnanti. Insegnamento per l'istruzione di base.

\section{PALAVRAS INICIAIS}

Embora o diagnóstico de Silva, Nóbrega-Therrien e Farias (2014) apontar que a formação inicial de professores é um dos principais objetos de estudos do campo formativo da docente no Brasil, haja vista que desde as primeiras décadas do século $X X$ uma série de produções são realizadas na área, a exemplo das investigações de Romanowski (2013) e André et. al. (1999), concorda-se com Dias e Passos (2016) que é relevante tratar também dos aspectos ligados as trajetórias histórico-políticas da formação, uma vez que esse enfoque recebe um menor número de produções. Nesse sentido, o presente artigo visa a contribuir com as discussões acerca dos elementos históricos e políticos relacionados a formação inicial de professores, tendo como objetivo pontuar, alicerçado em uma pesquisa de cunho documental e de revisão de literatura, as trajetórias histórico-políticas da formação docente para a educação básica.

Com relação a revisão de literatura, compõem entre outros, os trabalhos de Dias e Passos (2016), Dourado (2015; 2013), Gatti e Barreto (2009), Saviani (2009) e Tanuri (2000), bem como para a análise documental, foram utilizadas as diretrizes legais que tratam da formação de professores no Brasil, a exemplo, de Brasil (2015; 2014; 2017; 2002a, 2002b, 1961), para ilustrar. Cabe ressaltar que o entendimento preconizado no texto sobre a formação inicial de professores para a educação básica, compreende a atuação em todos os segmentos educativos, portanto, desde a educação infantil, passando pelo ensino fundamental e chegando ao ensino médio.

O recorte cronológico adotado no texto, se baseou na literatura especializada e na documentação legal e optou por fazer um balanço histórico panorâmico entre os anos de 1927, momento que Saviani (2009) elenca que ocorreram os primeiros debates acerca da formação de professores no Brasil, até $\mathrm{o}$ ano de 2015 quando se promulgou as Diretrizes Curriculares Nacionais (DCN's) para a Formação Inicial e Continuada de Professores, por meio da Resolução no 2 do Conselho Nacional de Educação (CNE) (BRASIL, 2015). Vale destacar que, apesar de novas discussões no âmbito das DCN's dos cursos de licenciaturas e do trabalho docente, entretanto em razão da escolha do período e do entendimento dos processos das (des)continuidades históricas, enfocou-se os dois marcos, com o objetivo de sistematizar as questões relativas a formação docente no Brasil. 
Desse modo, em função do recorte cronológico em longa duração, o texto se dividirá em mais dois momentos, excetuando-se as palavras iniciais e as considerações finais, com a finalidade de compreender e analisar as tramas histórico-políticas relativas a formação docente no Brasil. Portanto, a primeira seção discutirá o período dos anos de 1927-2006, baseado nas pesquisas de Saviani (2009) que corrobora que é nesse período que se tem as primeiras discussões acerca do processo formativo dos professores, sendo também o ano de 2006 emblemático para a proposição das DCN's e para o balanço do decênio de vigência da Lei de Diretrizes e Bases da Educação Nacional (LDB) № 9.394 de 1996, segundo o autor. O primeiro momento também discorrerá sobre as distintas concepções acerca dos tipos de formação e dos aspectos pedagógicos e dos currículos que foram preconizados.

Já o segundo momento discorrerá sobre o período de 2007-2015, enfocando as permanências e as descontinuidades dos cursos de licenciaturas e da fragmentação das legislações que não acenam para um cenário muito diferente do que já se vive. A seção também tratará da formação docente no interior das instituições de ensino superior (IES), entendendo suas limitações e falta de efetivação, bem como se refletirá a partir de Dias e Passos (2016) sobre alguns apontamentos que visam a formação mais consolidada e de qualidade socialmente referenciada para professores que terão a educação básica como espaço para o exercício profissional.

\section{Percursos histórico-políticos das primeiras discussões ao quadro formativo dos professores pós LDB de 1996}

Saviani (2009, p. 143-144) entende que a formação inicial de professores pode ser estudada a partir de seis momentos distintos, que cada um com uma particularidade, um marco, impactou as concepções, as identidades e os cursos formativos. Tais períodos são:

1. Ensaios intermitentes de formação de professores (18271890). Esse período se inicia com o dispositivo da Lei das Escolas de Primeiras Letras, que obrigava os professores a se instruir no método do ensino mútuo, às próprias expensas; estende-se até 1890, quando prevalece o modelo das Escolas Normais.

2. Estabelecimento e expansão do padrão das Escolas Normais (1890-1932), cujo marco inicial é a reforma paulista da Escola Normal tendo como anexo a escola-modelo.

3. Organização dos Institutos de Educação (1932-1939), cujos marcos são as reformas de Anísio Teixeira no Distrito Federal, em 1932, e de Fernando de Azevedo em São Paulo, em 1933. 
4. Organização e implantação dos Cursos de Pedagogia e de Licenciatura e consolidação do modelo das Escolas Normais (1939-1971).

5. Substituição da Escola Normal pela Habilitação Específica de Magistério (1971-1996).

6. Advento dos Institutos Superiores de Educação, Escolas Normais Superiores e o novo perfil do Curso de Pedagogia (1996-2006).

Desse modo, em uma organização dialógica e sintética com a proposição de Saviani (2009), concorda-se que desde a segunda década do século XIX, principalmente em razão do processo da independência, identifica-se de forma ainda incipiente, os primeiros esboços em prol da sistematização da instrução pública, por meio da escolarização formal, com o objetivo de fomentar a construção de uma identidade nacional. Cabe ressaltar que conforme estudado por Pereira, Felipe e França (2012), o que estava em jogo não era apenas a corroboração para um sentimento de formação do povo. O ideal de instruir vinha com uma inspiração da Revolução Industrial Inglesa e vislumbrava atender os interesses da burguesia local para a preparação de uma mão-de-obra que correspondesse com as necessidades do mundo do trabalho. Guardadas as proporções e idiossincrasias, perdura até a atualidade a intervenção de organismos que defendem uma formação precária e direcionada ao trabalho, não havendo na época e talvez ainda hoje, uma preocupação com a constituição integral e humana do sujeito, mas sim, a prevalência de um sentido econômico e desigual para a educação.

Nesse aspecto, em 1827 se promulga a lei que cria as Escolas de Primeiras Letras reverberando assim que a educação nacional deveria ser orientada pelo método mútuo ou Lancaster, registrando assim na lei que os professores deveriam ser formados dessa forma, baseando-se no treinamento de alunos mais desenvolvidos para contribuir com a aprendizagem dos discentes com mais dificuldades. Somente com o ato adicional de 1834, ocorre o entendimento que a formação inicial de professores deveria se dar, a exemplo de outros países, nas Escolas Normais. Destaca-se que conforme os apontamentos de Saviani (2009) e Tanuri (2000), o ato adicional de 1834 contribui com mudanças na Constituição outorgada de 1824, oferecendo mais autonomia as províncias, desde que respeitassem a legislação central. Em relação as Escolas Normais, Saviani (2009) destaca que havia uma subdivisão das instituições entre primária e superior. As primeiras formavam docentes para a atuação no ensino primário, o que poderia ser análogo ao ensino fundamental vigente contemporaneamente, enquanto as segundas formavam professores para a atuação no ensino secundário, o que poderia ser equivalente aos anos finais do ensino fundamental e ensino médio. Para o autor, a prevalência no contexto brasileiro foi das Escolas Normais Primárias.

No período inicial entre os anos de 1827-1890, Saviani (2009) compreende que em razão de muitas Escolas Normais não terem logrado êxito, 
por conseguinte, não ocorreu nem o acesso ampliado, nem com qualidade para a formação de novos docentes. Para Olinda (2005) os insucessos nos processos formativos foram proporcionados tanto pelo descaso dos governantes em termos de financiamento das instituições, bem como pela negligência com a formação pedagógica, face aos conteúdos específicos de outras áreas do conhecimento.

No que se refere ao segundo momento proposto por Saviani (2009) entre o período de 1890-1932, o autor identifica a expansão e a reorganização das Escolas Normais, por meio de reformas estaduais. Nessa época ocorreu o acréscimo de conteúdos nas grades curriculares, a maior ênfase em atividades práticas de ensino e a criação de escolas-modelo que eram anexadas às Escolas Normais, configurando-se como uma das principais mudanças no que toca a formação. Para Saviani (2009) e Tanuri (2000) foi significativo o número de novas instituições abertas em todo o país que se dedicavam a formar docentes. Olinda (2005) ainda afirma que a expansão das Escolas Normais contribuiu para o reendosso da perspectiva moderna da época que através da educação, poderia se galgar uma ascensão social, bem como o desenvolvimento do país. Contudo, em razão das centralizações institucionais e de interesses dissonantes entre as esferas do governo, a pretensa modernidade desejada não foi atingida e a expansão das Escolas Normais não conseguiu alcançar a grande parte da população das camadas populares que viviam apartadas dos privilégios da parca elite brasileira.

O terceiro período dividido por Saviani (2009) que enfoca entre os anos de 1932-1939, além de repensar os tipos de formação e os conteúdos dos planos curriculares, vai investir na pesquisa acerca da temática, se distinguindo assim, dos outros momentos já elencados. Desse modo, Vidal (2001, p. 79-80) afirma que

Com a reforma instituída pelo decreto n. 3.810, de 19 de março de $1932,[. .$.$] se propôs a erradicar aquilo que [...] se considerava$ o 'vício de constituição' das Escolas Normais, que, 'pretendendo ser, ao mesmo tempo, escolas de cultura geral e de cultura profissional, falhavam lamentavelmente nos dois objetivos'.

Para Tanuri (2000) a criação dos Institutos de Educação configuraram um novo modo de formar docentes, uma vez que as instituições representaram os espaços próprios para a formação de professores, a exemplo do Instituto de Educação do Distrito Federal, fundado em 1932 no Rio de Janeiro por Anísio Teixeira e do Instituto de Educação de São Paulo criado no ano seguinte, dirigido por Lourenço Filho e por Fernando de Azevedo, ambos nomes do movimento da Escola Nova. É esse grupo com ideias da inclusão das disciplinas pedagógicas, dentre outras mudanças, que capitanearam a criação e o desenvolvimento dos Institutos de Educação e das Escolas de Formação de Professores. As mudanças curriculares se referiram ao acréscimo de disciplinas, antes não 
existentes ou minoradas nas Escolas Normais, como matérias da área de Didática, Psicologia e Fundamentos da Educação, como Sociologia, História e Filosofia. Nessa direção, Saviani (2009, p. 146) afirma que "caminhava-se, pois, decisivamente rumo à consolidação de um modelo pedagógico-didático de formação docente que permitiria corrigir as insuficiências e distorções das velhas Escolas Normais [...]".

Contudo, Lopes (2007) discorda do exposto por Saviani (2009), em relação as dissonâncias presentes entre as propostas dos Institutos de Educação e as práticas das Escolas de Formação, em razão das discrepâncias sobre o prescrito e o praticado, registrado nos documentos e nas memórias dos sujeitos que viveram esse período formativo. Lopes (2007) a partir de suas investigações no Instituto de Educação do Distrito Federal, mostrou que embora o discurso e a presença marcante do Movimento Escolanovista, os currículos se basearam em uma concepção da Psicologia Comportamentalista mais estrita, o que reverberou na segregação da formação, calcada em uma prática enquadrada e hierárquica de aprendizagem e de relação com os alunos. A autora ainda destaca a forte presença feminina nos cursos de formação de professores de primeiras letras, apontando para o processo de feminização da docência, bem como nos faz refletir que apesar da emergência das ideias do Movimento da Escola Nova, as instituições responsáveis pelos processos formativos de educadores, não conseguiram se libertar das amarras das concepções entendidas como tradicionais. Destarte, Lopes (2007) entende que em razão da influência Escolanovista e das mudanças de cunho social, político e econômico, os Institutos de Educação foram elevados a nível superior, marcando a tônica da formação docente elencada por Saviani (2009).

O quarto período demarcado por Saviani (2009) entre os anos de 19391971, vão evidenciar a criação e implementação dos cursos de licenciaturas e de Pedagogia, bem como irá confirmar o modelo seguido pelas Escolas Normais. É com a homologação do Decreto Lei no 1.190 de 1939 que se fundam as Faculdades de Filosofia que segundo Cacete (2014) vão assumir a responsabilidade pela formação docente inicial e representaram espaço profícuo para a criação de vários cursos de licenciatura e de Pedagogia. Cacete (2014) chama atenção para que a depender do estado ou da região, as Faculdades de Filosofia também eram denominadas de Faculdades de Filosofia, Ciências e Letras. Para Tanuri (2000) ocorreu uma diferenciação formativa entre os cursos de licenciatura e o de Pedagogia: enquanto os primeiros formavam professores que atuariam em disciplinas específicas no ensino secundário, o segundo habilitariam bacharéis em educação e professores que atuariam nas Escolas Normais, que formavam docentes para o ensino primário. Vale ressaltar que os Institutos de Educação continuaram até a década de 1970 formando professores que poderiam lecionar nas Escolas Normais. Gatti e Barreto (2009) salientam ainda que, em sua gênese, tanto os cursos de licenciatura como o de Pedagogia 
foram concebidos na modalidade de bacharel, bastando apenas o cumprimento de um ano de disciplinas do campo educacional para obter o título de licenciado.

Para Cacete (2014) que estudou o período de 1939-1971, em específico a formação de professores para o ensino secundário, foi após a criação dos cursos de licenciatura e de Pedagogia que se instituiu a lógica do três mais um, demarcando a dicotomia entre as disciplinas de conhecimentos gerais e específicas de um ramo do conhecimento com os saberes pedagógicos, próprios da docência e reverberando na falta de relação com as atividades profissionais e suas identidades. Tal dualismo em segregar a formação de professores entre disciplinas consideradas teóricas e as práticas, relativas as metodologias de ensino e os conhecimentos pedagógicos, vão impactar a concepção e a disposição dos currículos dos cursos, gerando ecos que até hoje insistem em povoar os imaginários, quanto a ausência ou não de momentos práticos na formação ou a sua suposta disparidade e atribuição utilitarista do que se denomina teórico.

O processo de industrialização, o crescimento desordenado do espaço urbano e o golpe que instaurou a ditadura civil-militar foram alguns dos principais eventos que balançaram as estruturas sociopolíticas da fase de 1939-1971. Tais questões sociais impactaram as relações com o campo educacional, se manifestando nesse sentido com medidas legais, tal como o Decreto Lei ㄲo 4.244 de 1942 que foi responsável por sistematizar o ensino secundário em dois ciclos: o ginasial e o colegial, tendo o primeiro duração de quatro anos e o segundo de três anos (BRASIL, 1942). Outra medida foi o Decreto Lei no 8.529 de 1946 que propôs uma organização em âmbito nacional ao ensino primário (BRASIL, 1946). Nos anos de 1961 e 1968 foram promulgadas respectivamente a LDB, Lei no 4.024 e a Lei 5.540 que homologava a Reforma Universitária. Para Borges, Aquino e Puentes (2011) tais ordenamentos legais vão sistematizar e agir sobre a educação nacional, incluindo as diretrizes para a formação inicial de professores que terão a educação básica como espaço de exercício profissional.

O quinto momento proposto por Saviani (2009) retoma o período de 19711996, demarcando todos os processos ocorridos durante a ditadura civil-militar e as movimentações em prol da redemocratização do país. O regime político, assim como outros fatores sociais e econômicos impuseram mudanças ao campo educacional. Sendo assim, foi promulgada a Lei oㅜ 5.692 de 1971 que significou uma espécie de complementação a LDB de 1961, legislando sobre a educação básica, que assumia outra nomenclatura: de ensinos primário e secundário para primeiro e segundo graus (BRASI, 1971). No bojo dos novos arranjos legais, as Escolas Normais são extintas e é criado o Magistério, uma habilitação específica de segundo grau, que formava professores para a atuação nas quatro ou seis séries iniciais do primeiro grau. Tanuri (2000) salienta que para a atuação nos anos finais do primeiro e no segundo graus era necessária a 
formação no ensino superior. Sobre tais alterações na formação docente, Saviani $(2009$, p. 147) retrata que

\begin{abstract}
Pelo parecer n. 349/72 (Brasil-MEC-CFE, 1972), aprovado em 6 de abril de 1972, a habilitação específica do magistério foi organizada em duas modalidades básicas: uma com a duração de três anos (2.200 horas), que habilitaria a lecionar até a $4^{a}$ série; e outra com a duração de quatro anos (2.900 horas), habilitando ao magistério até a $6^{\underline{a}}$ série do $1^{\circ}$ grau. [...] Para as quatro últimas séries do ensino de $1^{\circ}$ grau e para o ensino de $2^{\circ}$ grau, a lei n. 5.692/71 previu a formação de professores em nível superior, em cursos de licenciatura curta (3 anos de duração) ou plena (4 anos de duração). Ao curso de Pedagogia, além da formação de professores para habilitação específica de Magistério (HEM), conferiu-se a atribuição de formar os especialistas em Educação, aí compreendidos os diretores de escola, orientadores educacionais, supervisores escolares e inspetores de ensino.
\end{abstract}

Nessa mesma direção, como pode-se observar a tônica do regime civilmilitar, a legislação que versava acerca da formação de professores foi alterada para atender interesses outros. Desse modo, Gatti e Barreto (2009), Saviani (2009) e Tanuri (2000) explicitaram a criação dos cursos de licenciatura curta como um caminho para a formação docente na época. De abordagem polivalente e precária, em três anos era possível se formar na habilitação de Estudos Sociais ou Ciências. Em razão do modelo tecnicista para a educação, as licenciaturas plenas, que se dedicavam por quatro anos a uma área específica do conhecimento, não eram as preconizadas pelas políticas públicas. Tanuri (2000) destaca que para o curso de Pedagogia teve uma reestruturação curricular, dividindo a formação a partir de uma adaptação do magistério para o ensino superior, oferecendo variadas habilitações, que fragmentavam 0 desenvolvimento e as identidades profissionais. Tal indefinição era observada no percurso histórico do curso de Pedagogia e do perfil de seus estudantes. Criado em 1939 pela força do Decreto Lei no 1.190, o curso já propunha uma duplicidade de habilitações: a de licenciados que trabalhariam na formação de outros professores nas Escolas Normais e na de bacharéis que seriam técnicos especialistas. Com o Parecer n²51 de 1962 emitido pelo Conselho Federal de Educação (CFE), deixa de forma nublada que o curso de Pedagogia poderia formar professores para o ensino primário. Em 1969, com o Parecer no 252 do CFE garantia a formação do professor primário no curso superior, aspecto que segundo Saviani (2009) e Tanuri (2000) vão abrir precedentes para que nos anos de 1980 e 1990 seja definido que para a atuação nos segmentos da educação infantil e ensino fundamental, a formação exigida seja a oferecida pelo curso de Pedagogia. 
Gatti e Barreto (2009) ainda destacam que na década de 1980 com o intuito de qualificar e ampliar o número de professores que atuariam no primeiro grau, foram criados os Centros de Formação e Aperfeiçoamento do Magistério (CEFAM's) que principalmente atuavam frente aos docentes formados em nível médio, a partir de cursos de rápida duração. Com a promulgação da LDB de 1996, os centros foram extintos. Gatti e Barreto (2009) entendem os CEFAM's como dispositivos da Lei no 7.044 de 1982 que mudou o que era referente à formação docente no âmbito da Lei oㅜ 5.692 de 1971. Para as autoras, os centros seriam a figuração das novas medidas legais para o campo da formação docente.

Com o período que marca o início do processo de redemocratização no Brasil e fim do regime civil-militar, vários grupos ligados a sociedade civil e a entidades de caráter científico-profissional, tal como a Associação Nacional pela Formação dos Profissionais da Educação (ANFOPE), entre outras, reivindicaram mudanças na educação básica e no ensino superior, dentre elas, as que se referem a formação docente, estão a remodelagem das grades curriculares dos cursos de Pedagogia e de Licenciaturas, bem como a defesa de que a docência deveria ser o pilar central da formação de novos professores. Gatti e Barreto (2009) marcaram que uma das principais consequências de se postular a docência como núcleo da formação, é se implicar, constituir e legitimar a identidade profissional do professor, reconhecendo os saberes pedagógicos como os específicos do educador, não fomentando assim, a continuidade da falsa dicotomia formativa entre bacharel e licenciado. Todos pesquisam e/ou devem pesquisar, bem como todos comunicam e/ou devem comunicar, em algum nível ou medida.

O último momento definido por Saviani (2009) corresponde ao período de 1996-2006, que marca a temporalidade, a promulgação e os dez anos posteriores da LDB. Bazzo (2004) entende que a LDB de 1996 não contemplou as demandas reivindicadas pela ANFOPE e por outros grupos, encaminhando assim, para a desvalorização e a desprofissionalização da docência. Acerca da formação docente, a LDB sob o título "Dos profissionais da Educação", no Título $\mathrm{VI}$, dispõem os artigos 61 a 67 que versam sobre o assunto. $\mathrm{O}$ artigo 62 (BRASIL, 1996) em específico afirma que

A formação de docentes para atuar na educação básica far-se-
á em nível superior, em curso de licenciatura, de graduação
plena, em universidades e institutos superiores de educação,
admitida, como formação mínima para o exercício do magistério
da educação infantil e nas quatro primeiras séries do ensino
fundamental, a oferecida em nível médio, na modalidade normal.

A LDB pode ser compreendida em diversas faces. Ao ponto que postulou a necessidade de formação superior para os professores que atuam nos ensinos 
fundamental e médio, o que representa um ponto positivo, entretanto, como a Lei não preconizou o espaço universitário como o específico para a formação docente, abriu-se espaço para que outras instituições, afastadas da pesquisa e da extensão, sem estrutura humana e material, assumissem essa formação. Cabe destacar que a maioria desses espaços eram de natureza privada, que ofereciam formações aligeiradas e de caráter duvidoso. Cunha (2003) aponta que durante o primeiro mandato do governo de Fernando Henrique Cardoso (FHC) (PSDB-SP), entre os anos 1995-2003, houve uma reestruturação das IES, chancelado pelo Decreto № 2.306 de 1997 que entre as opções de universidade, faculdade integrada, centros universitários ou faculdades, institutos ou escolas superiores, que favoreceram, principalmente, os grupos particulares.

Para Cunha (2003) as políticas educacionais para o ensino superior do governo FHC estiveram totalmente a serviço da lógica neoliberal e mercadológica do ensino superior, fomentando as desigualdades, retirando investimento das universidades públicas e corroborando com o crescimento das instituições privadas. Com o paralelismo da LDB as indicações do Banco Mundial e todo o itinerário político sob a égide da reestruturação produtiva e das demandas mundiais do mercado, os cursos de licenciaturas e de Pedagogia foram moldados para serem subservientes aos interesses do capital. Nesse sentido, data de 2002 as Diretrizes Nacionais Curriculares para os Cursos de Licenciaturas (DCN's), bem como as Resoluções $n^{\circ} 01$ e 02 do CNE, que dispunham de orientações para os cursos de formação inicial docente. Vale ressaltar que é com a LDB de 1996 que se efetiva o Plano Nacional de Educação (PNE) que foi homologado pela Lei 10.172 de 2001 (BRASIL, 2001). Cunha (2003) destaca que no documento não existe perspectiva para a formação docente em âmbito inicial, mas sim, para Dias e Passos (2016) ocorre um retrocesso a medida que se valida formação média para educadores infantis e professores do ensino fundamental.

Tanto as DCN's para a Formação de Professores da Educação Básica quanto a Resolução no 01 do CNE (BRASIL, 2002a), era possível se observar um conjunto de premissas que serviriam para nortear os horizontes formativos dos cursos de graduação de licenciaturas. Porém, Bazzo (2004) destaca que as disposições sofreram fortes críticas de entidades da sociedade civil e científicoprofissionais, por reestabelecer toda a matriz da formação docente em uma estrutura tecnicista, instrumentalizadora, que já havia se apropriado do vocabulário neoliberal em suas práticas: a gestão, a competência e as metas eram os enfoques da profissão. Bazzo (2004) entende consonante a demais representações dos profissionais da educação, que a adesão a perspectiva econômica na formação de professores é limitada já que não concebe o trabalho colaborativo e não objetiva refletir sobre o contexto e os demais interlocutores.

Logo, encaminhando para considerações finais acerca das trajetórias histórico-políticas da formação de professores no período de 1927 a 2006, pode- 
se observar que a educação como produto e produtora da realidade social sofrerá mudanças e disputas em função dos arranjos de poder, de interesse e das configurações socioeconômicas. São em tais jogos de força que a formação docente se insere, marcadas entre descontinuidades e retrocessos, que são ilustrados nas legislações e documentos oficiais. Com o exposto, não é difícil concluir a ausência de políticas de Estado para a educação, comprometida com uma formação sólida para os professores vislumbrando a transformação social. Destarte, uma série de legislações fragmentadas e desconexas visam suprir a falta de uma ação orgânica e efetiva para o campo educacional e de formação dos profissionais da educação. É esse debate que será a tônica das discussões da próxima seção.

\section{Reuni e DCN's como reflexos das políticas educacionais fragmentadas}

Dando continuidade a reflexão histórico-política das trajetórias de formação inicial de professores, depois de retratar o período compreendido entre 1927-2006, dar-se-á enfoque as nuances legais no recorte entre os anos de 2007 a 2015. Como já anunciado no final da seção anterior, os processos político, histórico e legal das políticas de formação docente se revelaram desconexas, fragmentadas e em desacordo com as manifestações de entidades de classes científicas e profissionais, a exemplo da ANFOPE, bem como o Fórum Nacional de Diretores de Faculdades, Centros de Educação ou Equivalentes das Universidades Públicas Brasileiras (FORUMDIR), a Associação Nacional de Pós-Graduação e Pesquisa em Educação (ANPEd), entre outros.

Maués e Souza (2016) e Sousa e Coimbra (2015) destacam que o Programa de Apoio a Planos de Reestruturação e Expansão das Universidades Federais (REUNI), homologado pelo Decreto no 6.096 de 2007 (BRASIL, 2007), foi uma das primeiras ações governamentais do período enfocado que chancelou um acordo entre os órgãos superiores e a administração universitária com a finalidade de aumentar o número de professores e demais profissionais formados em um prazo de cinco anos. O Decreto dispõe que em caso de cumprimento da proposta, o Governo Federal retribuiria a IES com até vinte por cento do orçamento destinado ao pagamento de recursos humanos e custeio básico. Em relação a formação inicial de professores, a resposta dada a essa política foi que pode ser observado um aumento expressivo dos cursos de licenciaturas noturnos em campi localizados no interior dos estados. Mesmo com críticas a real expansão e sua efetivação, o que foi notado é que a quantidade foi preconizada em detrimento da qualidade, uma vez que as instituições careciam de laboratórios, bibliotecas, recursos didático-pedagógicos e de políticas para a permanência, no que se refere a alojamentos e alimentação, principalmente para aqueles estudantes de camada popular e das IES 
interiorizadas. Para Maués e Souza (2016) e Sousa e Coimbra (2015) ainda pesam que nesse cenário é relevante considerar a escalada do ensino a distância, tanto no setor público como no privado, demarcando que no último o processo costuma ser mais precário e mercadológico, como também os autores entendem que muitos desses cursos isolados e estruturados nessa condição, contribuem para o fracasso da formação docente, no sentido da ausência de reflexão e de pesquisa no âmbito formativo.

A próxima política que atuou no disciplinamento da ação da Coordenação de Aperfeiçoamento de Pessoal de Nível Superior (CAPES) foi promovida pelo Decreto oㅡ 6.755 de 2009 (BRASIL, 2009) que promulgou a Política Nacional de Formação dos Profissionais do Magistério da Educação Básica, sistematizando programas formativos em fases inicial e continuada para os docentes. Abdalla (2012) entende que a política gerou uma noção de colaboração entre as três instâncias federativas, fomentando a criação do Plano Nacional de Formação de Professores da Educação Básica (PARFOR). O Plano (BRASIL, 2009) foi realizado de modo urgente, atuando da seguinte forma: oferecimento de formação pedagógica para profissionais formados apenas na modalidade bacharelado; possibilidade de segunda licenciatura em área diferente da formação, com carga de 800 a 1.200 horas e, primeira licenciatura, para aqueles que não possuíam formação de nível superior, em 2.800 horas. Cabe ressaltar que em razão da Resolução oㅡ 02 do CNE de 2015 ocorreu uma reestruturação dos cursos de formações inicial e continuada de professores e da divulgação das novas DCN's formativas e que o Decreto $n^{\circ} 6.755$ de 2009 foi atualizado e revogado pelo Decreto № 8.752 de 2016. Investigações como de Souza (2017) e de Amorim e Medeiros (2016) apontam de forma reflexiva em relação ao PARFOR, que o Plano agravou as desigualdades e tornou mais precária a formação inicial docente, a medida que cerceou e generalizou propostas formativas, não observou as demandas e os contextos locais para a proposição de propostas, atrasos constantes de financiamentos e em razão da falta de estrutura e da carga horária reduzida, a ausência dos pilares universitários de pesquisa e de extensão durante a formação. Vale lembrar que as considerações críticas reconhecem que em alguma dimensão, o PARFOR contribuiu com alguns avanços, como destacam Amorim e Medeiros (2016), os professores que tiveram contato com as IES públicas, sejam na primeira ou segunda licenciatura, avaliaram como positiva a experiência, bem como possibilitou alguma reflexão perante suas práticas pedagógicas.

O Plano Nacional de Educação (PNE) foi uma outra política instituída no período enfatizado. Homologado pelo Decreto Lei 13.005 de 2014, é um documento que revela uma organização sistemática de princípios, diretrizes, estratégias e metas que visam à melhoria e à qualidade da educação brasileira, tendo uma vigência de dez anos, a partir da data de criação e de aprovação. No que se refere à formação inicial de professores, o Plano (BRASIL, 2014) não aborda de modo explícito e claro os processos formativos docentes, em um 
corpo de vinte metas e dez diretrizes, fazendo somente uma vaga menção quando aponta as ações para cada nível de ensino. Ilustra-se assim, um quadro histórico supracitado, de ausência de interesse público em se realizar uma política de Estado para o campo educacional.

Em relação a Resolução nº 02 de 2015 do CNE (BRASIL, 2015) ela merece uma especial atenção por promulgar as DCN's que vão se ocupar das formações inicial e continuada em cursos de primeira e segunda licenciaturas, bem em formações pedagógicas para bacharéis. Segundo Dourado (2015), em um olhar retrospectivo para as políticas públicas de formação, as DCN's de 2015 são as que representam de forma mais consolidada diretrizes e orientações para o processo formativo, associando as dimensões inicial e continuada como faces de um mesmo desenvolvimento, embora ocorram em períodos distintos. Assim, para o autor, o dispositivo legal contribuiu para valorização dos entendimentos acerca da formação e da profissão docente, já que reconhece os fatores relacionados as condições de trabalho, aos planos de carreira e aos salários. Dias e Passos (2016) salientam que o texto das DCN's ainda englobam a partir dos sintagmas nominais profissionais do magistério, aqueles professores que não tinham formação universitária, para o enquadro da lei. Tanto Dias e Passos (2016) quanto Dourado (2015) apontam que o documento de 2015 vislumbra um diálogo fortuito e uma tentativa de unificação curricular, quando se dispõem em paralelos as diretrizes para os professores e as da educação básica. Dessa forma, são as Diretrizes de 2015 que oferece substrato para as políticas de formação docente registradas pelo Decreto no 6.755 de 2009 (BRASIL, 2009), que articulam um regime de colaboração entre as redes e a União, estados e municípios. Ademais, a Conferência Nacional de Educação (CONAE, 2014) chancelou os conteúdos que formaram as Diretrizes, no que tange a valorização e a formação dos professores. Para Dourado (2013) as DCN's correspondentes a Resolução no 02 de 2015 do CNE relaciona as demandas da comunidade educativa com os processos de formação, afirmando no Artigo 3, parágrafo 6 (BRASIL, 2015) que

O projeto de formação deve ser elaborado e desenvolvido por meio da articulação entre a instituição de educação superior e o sistema de educação básica, envolvendo a consolidação de fóruns estaduais e distrital permanentes de apoio à formação docente, em regime de colaboração, e deve contemplar:

I - sólida formação teórica e interdisciplinar dos profissionais;

II - a inserção dos estudantes de licenciatura nas instituições de educação básica da rede pública de ensino, espaço privilegiado da práxis docente;

III - o contexto educacional da região onde será desenvolvido;

IV - as atividades de socialização e a avaliação de seus impactos nesses contextos;

V - a ampliação e o aperfeiçoamento do uso da Língua Portuguesa e da capacidade comunicativa, oral e escrita, como 
elementos fundamentais da formação dos professores, e da aprendizagem da Língua Brasileira de Sinais (Libras);

$\mathrm{VI}$ - as questões socioambientais, éticas, estéticas e relativas à diversidade étnico-racial, de gênero, sexual, religiosa, de faixa geracional e sociocultural como princípios de equidade.

Após propormos uma visada panorâmica nos marcos elencados de natureza histórico-política para a formação de professores no período de 20072015, pode-se observar que embora a movimentação densa de perspectivas legais (DOURADO, 2013), ocorre na reflexão a persistência de um caráter fragmentado e inorgânico para os processos formativos da docência, sem um diálogo exitoso com os órgãos e associações representativas de classes científico-profissionais e da sociedade civil, uma vez que as reivindicações e os textos são dissonantes. Portanto, desafios entre as instâncias governamentais e as relações com as IES, geram um quadro que afeta a formação docente e que é pregresso e às vezes intocável as dinâmicas legais. Sendo assim, alguns desses desafios poderiam ser caracterizados pelo fomento da dicotomia entre cursos de licenciatura e bacharelado; ausência de discussões profícuas acerca das grades curriculares das licenciaturas; questões dos jogos de poder e de interesses das instituições e de seus núcleos formadores quanto as propostas curriculares para os cursos e necessidade de revisão e de construção constantes de projetos pedagógicos dos cursos, em consonância com as demandas da comunidade e do contexto local, respeitando as diretrizes novas e já existentes. As questões elencadas são indiciosas perante a uma miríade de outros fatores que reendossam a diversidade relativa a formação.

Contudo, o presente artigo ciente da pluralidade, empreendeu uma tentativa de contribuir com a reflexão dos desafios do desenvolvimento da docência, a partir de um olhar em longa duração para as perspectivas históricas e político-legais. Destarte, em face ao exposto e discutido, entende-se que em razão do caráter fragmentado das políticas educativas do Brasil entre o período de 2007-2015, o quadro da formação docente se evidencia cada vez mais desigual e emblemático. Nas considerações finais, discorrer-se-ão em acordo com Dias e Passos (2016) sobre os possíveis horizontes para uma formação docente comprometida com a qualidade da educação pública e com a mudança social.

\section{À guisa das considerações finais}

Durante as trajetórias histórica, política, social e econômica a formação inicial de professores atravessou uma série de cenários distintos que discutiam os diferentes espaços para o desenvolvimento dos processos formativos, as várias facetas da identidade, as relações profissionais, bem como os modelos dos cursos e seus currículos, chancelados por dispositivos legais. Concordando 
com Dias e Passos (2016) compreende-se que tal quadro formativo foi gerado em razão da ausência de políticas públicas em âmbito nacional para a pauta, marcando a predominância de interesses outros para a estruturação do campo da educação. A fragmentação dos dispositivos legais também é entendida como reflexo de jogos e tramas densas de poder, que encaminharam propositalmente a caminhos sem saídas e conexões.

Propondo trilhas e olhares que objetivem a ampliação da qualidade, dos horizontes e do compromisso social da docência e da educação, elenca-se como Dias e Passos (2016) a importância de políticas públicas que coadunem a sua ação na relação coeva e concomitante das IES e dos estabelecimentos de educação básica, haja visto suas configurações formativas, direcionando para a valorização do professor e do seu trabalho. Ademais é preciso articular os planos e projetos internos da instituição de formação de professores em torno de objetivos e propósitos comuns, que direcionem as demandas formativas para a "compreensão da dimensão ética, social, política, cultural, econômica, da profissão" e os "seus fundamentos psicológicos, pedagógicos, históricos, filosóficos" (DIAS; PASSOS, 2016).

À guisa das considerações finais se considera, no sentido do reconhecimento, o relevo impresso também no debate acerca da formação continuada e de seus percursos histórico, político, legal, social e econômico, mesmo não sendo o objetivo do presente texto, que no entanto, compreende que a formação é um processo contínuo, desenvolvido ao longo da vida e que portanto, apenas sua fase inicial não seria suficiente. Logo, a partir de uma análise holística, implicada e comparativa, se propôs refletir acerca dos processos de formação de professores, sobretudo o inicial, porém sem se desconsiderar o continuado, visando pensar sobre os limites e as possibilidades do campo ao longo do tema. Assevera-se que as indicações deixadas não têm um caráter de receituário, mas sim, de responder a alguns anseios e oferecer outras interpretações das dinâmicas histórico-políticas da formação docente no contexto brasileiro.

\section{REFERÊNCIAS}

ABDALLA, Maria de Fátima Barbosa. Políticas de Formação de Professores: desafios e perspectivas. Collatio. São Paulo, p. 23-32, abr./jun. 2012.

AMORIM, Jamira Lopes de; MEDEIROS, Emerson Augusto de. A política nacional de formação de professores/as da educação básica e o PARFOR/UERN: expansão, desafios e perspectivas. Educação \& Linguagem. São Paulo, v. 19, n. 1, p. 125-154, jan./jun. 2016.

ANDRÉ, Marli et al. Estado da Arte da Formação de Professores no Brasil. Educação e Sociedade. Campinas, ano XX, n. 68, p. 301-309, dez. 1999. 
BAZZO, Vera Lúcia. Os Institutos Superiores de Educação ontem e hoje. Educar em Revista. Curitiba, v. 20, n. 23, p. 267-283, jun. 2004.

BORGES, Maria Célia; AQUINO, Orlando Fernández; PUENTES, Roberto Valdés. Formação de Professores no Brasil: história, políticas e perspectivas. Revista HISTEDBR On-line. Campinas, v. 11, n. 42, p. 94-112, jun. 2011.

BRASIL. Decreto-Lei no 4.244, de 09 de abril de 1942. Lei orgânica do ensino secundário. Presidência da República. Casa Civil. Subchefia para Assuntos Jurídicos. Rio de Janeiro: RJ, 1942.

BRASIL. Decreto-Lei no 8.529, de 02 de janeiro de 1946. Lei Orgânica do Ensino Primário. Câmara dos Deputados. Brasília: DF, 1946.

BRASIL. Decreto № 6.096, de 24 de abril de 2007. Institui o Programa de Apoio a Planos de Reestruturação e Expansão das Universidades Federais - REUNI. Presidência da República. Casa Civil. Subchefia para Assuntos Jurídicos. Brasília: DF, 2007.

BRASIL. Decreto № 6.755, de 29 de janeiro de 2009. Institui a Política Nacional de Formação de Profissionais do Magistério da Educação Básica, disciplina a atuação da Coordenação de Aperfeiçoamento de Pessoal de Nível Superior - CAPES no fomento a programas de formação inicial e continuada, e dá outras providências. Diário Oficial da União. Brasília, DF, 2009.

BRASIL. Lei ํㅜ 5.540, de 28 de novembro de 1968. Fixa normas de organização e funcionamento do ensino superior e sua articulação com a escola média, e dá outras providências. Presidência da República. Casa Civil. Subchefia para Assuntos Jurídicos. Brasília: DF, 1968.

BRASIL. Lei no 5.692, de 11 de agosto de 1971. Fixa Diretrizes e Bases para o ensino de $1^{\circ}$ e $2^{\circ}$ graus, e dá outras providências. Presidência da República. Casa Civil. Subchefia para Assuntos Jurídicos. Brasília: DF, 1971.

BRASIL. Lei no 9394, de 20 de dezembro de 1996. Dispõe sobre as Diretrizes e Bases da Educação Nacional. Brasília, DF: MEC, 1996.

BRASIL. Lei no 10.172, de 09 de janeiro de 2001. Aprova o Plano Nacional de Educação e dá outras providências. Presidência da República. Casa Civil. Subchefia para Assuntos Jurídicos. Brasília: DF, 2001.

BRASIL. Lei $n^{\circ} 13.005$, de 25 de junho 2014. Aprova o Plano Nacional de Educação - PNE 2014-2024 e dá outras providências. Presidência da República. Casa Civil. Subchefia para Assuntos Jurídicos. Brasília: DF, 2014.

BRASIL. Resolução CNE/CP no 1, de 18 de fevereiro de 2002. Institui Diretrizes Curriculares Nacionais para a Formação de Professores da Educação Básica, em nível superior, curso de licenciatura, de graduação plena. Diário Oficial da União. Brasília, DF, 2002a.

BRASIL. Resolução CNE/CP n 2, de 19 de fevereiro de 2002. Institui a duração e a carga horária dos cursos de licenciatura, de graduação plena, de formação de professores da Educação Básica em nível superior. Diário Oficial da União. Brasília, DF, 2002b. 
BRASIL. Resolução CNE/CP no 02, de 01 de julho de 2015. Define as Diretrizes Curriculares Nacionais para a formação inicial em nível superior (cursos de licenciatura, cursos de formação pedagógica para graduados e cursos de segunda licenciatura) e para a formação continuada. Diário Oficial [da] República Federativa do Brasil. Brasília, DF, 2015.

CACETE, Núria Hanglei. Breve história do ensino superior brasileiro e da formação de professores para a escola secundária. Educação e Pesquisa. São Paulo, v. 40, n. 4, p. 1061-1076, out./dez. 2014.

CONAE. Documento Final da Conferência Nacional de Educação: O PNE na Articulação do Sistema Nacional de Educação. Brasília: DF, nov. 2014. Disponível em: http://fne.mec.gov.br/images/doc/DocumentoFina240415.pdf. Acesso em: ago. 2020.

CUNHA, Luiz Antônio. O Ensino Superior no Octênio FHC. Educação e Sociedade. Campinas, v. 24, n. 82, p. 37-61, abr. 2003.

DIAS, Ana Maria lorio; PASSOS, Carmensita Matos Braga. Passado e presente na formação de professores: por entre perspectivas históricas, legais e políticas. Revista Internacional de Formação de Professores. Itapetininga, v. 1, n. 2, p. 85-108, 2016.

DOURADO, Luiz Fernandes. A Formação de Professores e a Base Comum Nacional: questões e proposições para o debate. Revista Brasileira de Política e

Administração Educacional. Goiânia, v. 29, n.2, p. 367-388, maio/ago. 2013.

DOURADO, Luiz Fernandes. Diretrizes curriculares nacionais para a formação inicial e continuada dos profissionais do magistério da educação básica: concepções e desafios. Educação \& Sociedade. Campinas, v. 36, n. 131, p. 299-324, abr./jun. 2015.

GATTI, Bernardete Angelina; BARRETTO, Elba Siqueira de Sá. Professores do Brasil: impasses e desafios. Brasília: UNESCO, 2009.

LOPES, Sonia de Castro. A estrutura curricular da escola de professores do Instituto de Educação do Rio de Janeiro (1932-1939): representações acerca de uma nova cultura pedagógica. Educação em Questão. Natal, v. 28, n. 14, p. 96-120, jan./jun. 2007.

MAUÉS, Olgaíses Cabral; SOUZA, Michele Borges de. Precarização do trabalho docente da educação superior e os impactos na formação. Em Aberto. Brasília, v. 29, n. 97, p. 73-85, set./dez. 2016.

OLINDA, Ercília Maria Braga de. Formação Integral do educando no Tempo da Escola Normal. Fortaleza: Expressão gráfica Editora, 2005.

PEREIRA, Lilian Alves; FELIPE, Delton Apdo; FRANÇA, Fabiane Freire. Origem da escola pública brasileira: a formação do novo homem. Revista HISTEDBR On-line. Campinas, v. 12, n. 45 especial, p. 239-252, maio 2012.

ROMANOWSKI, Joana Paulin. Tendências da Pesquisa em Formação de Professores. Atos de Pesquisa em Educação. Blumenau, v. 8, n. 2, p. 479-499, maio/ago. 2013. 
SAVIANI, Dermeval. Formação de professores: aspectos históricos e teóricos do problema no contexto brasileiro. Revista Brasileira de Educação. Rio de Janeiro, v. 14, n. 40, p. 143-155, jan./abr. 2009.

SILVA, Silvina Pimentel; NÓBREGA-THERRIEN, Silvia Maria; FARIAS, Isabel Maria Sabino de. Produções sobre a formação de professores no EPENN: análise do período 2003 a 2011. In: GOMES, Alfredo Macedo; LEAL, Telma Ferraz (org).

Pesquisas em Educação nas regiões norte e nordeste: balanço e perspectivas. 1 ed. Recife: Editora UFPE, 2014. p. 127-152.

SOUSA, Ana Paula Ribeiro de; COIMBRA, Leonardo José Pinho. As licenciaturas interdisciplinares e o processo de expansão das IFES: implicações para a formação de professores. Revista HISTEDBR On-line. Campinas, v. 15, n. 65 especial, p. 141-159, out. 2015.

SOUZA, Valdinei Costa. Qualidade da formação de pedagogos na perspectiva da oferta do Parfor presencial. Educação e Pesquisa. São Paulo, v. 43, n. 1, p. 81-96, jan./mar. 2017.

TANURI, Leonor Maria. História da formação de professores. Revista Brasileira de Educação. Rio de Janeiro, n. 14, p. 61-88, maio/ago. 2000.

VIDAL, Diana Gonçalves. O exercício disciplinado do olhar: livros, leituras e práticas de formação docente no Instituto de Educação do Distrito Federal (1932-1937).

Bragança Paulista: EDUSF, 2001. p. 79-80. 